\title{
Faktor yang berhubungan dengan tingkat depresi pada pasien gagal ginjal kronis yang menjalani tindakan hemodialisa
}

\author{
Indra Maulana ${ }^{1}$, Iwan Shalahuddin ${ }^{2 *}$, Taty Hernawaty ${ }^{3}$ \\ 1,2,3Fakultas Keperawatan Universitas Padjadjaran Bandung Jawa Barat, Indonesia \\ *Email: shalahuddin@unpad.ac.id
}

\author{
Abstract \\ Psychosocial factors: The depression level in patients with chronic kidney disease \\ maintained on dialysis
}

Background: Chronic renal failure undergoing hemodialysis therapy in the world is almost 1.5 million people, and in Indonesia there are approximately 0.2 people with chronic renal failure undergoing hemodialysis therapy. The impact of hemodialysis on the physical that will occur in patients become weak tired in living their daily lives, against the psychological impact that will occur on sleep problems, impurity and depression, the impact on social and economic conditions that will occur to patients on social relationships, and on the environment the client will also have an impact on the social environment in which he lives. Therefore hemodialysis therapy will have an impact on the quality of life of patients.

Purpose: To determine Psychosocial factors: the depression level in patients with chronic kidney disease maintained on dialysis

Method: A descriptive correlational study by a cross sectional design approach. The sample used was 40 respondents, data collection techniques using questionnaires and direct observation with results calculated based on the total answers to questions given by respondents with criteria: score $<17=$ no sign of depression, score 18$24=$ mild depression, score $25-34=$ moderate depression and a score of 35-51 = severe depression, while the bivariate test used chi-square

Results: There was a relationship among factors such as: age, educational, sex, duration of maintaine of hemodialysis therapy and sleep patterns with the depression level in patients with chronic kidney disease under maintained on dialysis at Garut dr. Slamet Hospital.

Conclusion: Health workers (nurses) to provide motivational and therapeutic informing in implementing hemodialysis therapy so that patients are more excited and better understand the importance of hemodialysis and to reduce the level of depression.

\section{Keywords: Depression level; Patients; Chronic kidney disease; Dialysis}

Pendahuluan: Penyakit gagal ginjal kronik yang menjalani terapi hemodialisis di dunia hampir sekitar 1,5 juta orang, dan di indonesi hampitr sekitar 0,2 jiwa penderita gagal ginjal kronik yang menjalani terapi hemodialisis. Dampak hemodialisis terhadap fisik yang akan terjadi pada pasien menjadi lemah lelah dalam menjalani kehidupan sehari-hari, terhadap psikologis dampak yang akan terjadi pada masalah tidur, kecemasaan dan depresi, dampak terhadap sosial dan ekonomi yang akan terjadi pada pasien pada hubungan sosialnya, dan pada lingkungan klien juga akan berdampak pada sosial lingkungan dimana dia tinggal. Maka dari itu terapi hemodialisis akan berdampak pada kualitas hidup pasien.

Tujuan: Mengetahui faktor-faktor yang berhubungan dengan tingkat depresi pada pasien gagal ginjal kronis yang menjalani tindakan Hemodialisa

Metode: Menggunakan rancangan deskriptif korelasional dengan pendekatan desain cross sectional dengan sampel sebanyak 40 responden, teknik pengambilan data menggunakan kuesioner dan observasi langsung dengan hasil dihitung berdasarkan total jawaban dari pertanyaan yang diberikan responden dengan kriteri skor < 17 = tidak ada depresi, skor 18-24 = depresi ringan, skor 25-34= depresi sedang dan skor 35-51= depresi berat sedangkan uji bivariat menggunakan chi-square. 
Faktor yang berhubungan dengan tingkat depresi pada pasien gagal ginjal kronis yang menjalani tindakan hemodialisa

Hasil: Menunjukan adanya hubungan antara faktor : usia, pendidikan, jenis kelamin, lamanya periode menjalani terapi hemodialisa dan pola tidur. Semua faktor tersebut sangat berhubungan dengan tingkat depresi pada pasien gagal ginjal kronik yang menjalani tindakan hemodialisa di Ruang Hemodialisa RSUD dr. Slamet Garut.

Simpulan: Petugas kesehatan (perawat) agar memberikan motivasi dan terapeutik informing dalam pelaksanaan terapi hemodialisa agar pasien lebih bersemangat dan lebih memahami pentingnya hemodialisa serta untuk mengurangi tingkat depresi.

\section{Kata Kunci: Tingkat depresi; Gagal ginjal Kronis; Hemodialisa}

\section{PENDAHULUAN}

Manusia pada dasarnya menginginkan dirinya selalu dalam kondisi yang sehat, baik sehat secara fisik ataupun psikis, karena hanya dalam kondisi yang sehat manusia akan dapat melakukan segala sesuatu secara optimal.Tetapi pada kenyataannya selama rentang kehidupannya, manusia selalu dihadapkan pada permasalahan kesehatan dan salah satunya berupa penyakit yang diderita.Jenis penyakit yang diderita bentuknya beraneka ragam, ada yang tergolong penyakit ringan dimana dalam proses pengobatannya relatif mudah dan tidak terlalu menimbulkan tekanan psikologis pada penderita. Tetapi ada juga penyakit yang tergolong berat yang dianggap sebagai penyakit yang berbahaya dan dapat menggangukondisi emosional, salah satunya adalah penyakit gagal ginjal kronis (Romadhoni, 2012; Nurmalika, 2010; Faizzah, 2017).

Menurut World Health Organization (WHO) di dunia hampir sekitar 500 juta orang yang mengalami gagal ginjal kronik dan diantaranya sekitar 1,5 juta orang menjalani terapi hemodialisis World Health Organization. Berdasarkan data Mortality WHO South East Asia Region pada tahun 2010-2012 terdapat 250.217 jiwa penderita penyakit gagal ginjal kronik (Hutajulu, 2018; Wong, \& Sarjana, 2017; ).

Menurut Riskesdas 2013 dengan populasi usia muda 12-25 tahun yang terdiagnosa gagal ginjal kronik sebesar 0,2\% angka kejadian tersebut lebih rendah di bandingkan dengan negara-negara lain, ada juga hasil penelitian perhimpunan Neprologi Indonesia (Pernepri, 2006) yang mendapatkan prevalensi sebesar 12,5\%. Hal ini karena Riskesdas 2013 hanya menangkap orang yang terdiagnosis penyakit gagal ginjal kronik sedangkan sebagian besar penyakit gagal ginjal kronik baru terdiagnosis pada tahap lanjut dan akhir.

Dampak hemodialisis terhadap fisik yang akan terjadi pada pasien yaitu menjadi lemah lelah dalam menjalani kehidupan sehari-hari terutama setelah dilakukan hemodialisis, kelemahan dan kelelahan pada pasien hemodialisis diakibatkan karena anemia yang disebabkan oleh menurunnya produksi eritropoetin akibat kerusakan fungsi ginjal (Novitasari, \& Hidayati, 2015; Anggraini, 2016; Wijayanti, Dinarwiyata, \& Tumini, 2018). Dampak psikologi atau spiritual dari tindakan hemodialisis sangat kompleks dan berhubungan dengan faktor fsiologi. Depresi berhubungan dengan status kesehatan fisik, masalah tidur dan kecemasan. Dampak psikologis dan spiritual ini sangat berpengaruh terhadap kualitas hidup pasien (Lase, 2011; Tokala, Kandou, \& Dundu, 2015; Rahman, Kaunang, \& Elim, 2016).

Bagi penderita gagal ginjal kronis, hemodialisa akan mencegah kematian. Namun demikian, hemodialisa tidak menyembuhkan atau memulihkan penyakit ginjal dan tidak mampu mengimbangi hilangnya aktifitas metabolik atau endokrin yang dilaksanakan oleh ginjal dan dampak dari gagal ginjal serta terapi terhadap kualitas hidup pasien. Pasien harus menjalani dialisa sepanjang hidupnya atau sampai mendapat ginjal baru melalui operasi pencangkokan. Menurut hasil penelitian yang menyatakan bahwa tahun 2007 di dunia ini lebih dari 500 juta orang mengalami penyakit ginjal kronik dan sekitar 1,5 juta orang harus menyadari hidup bergantung kepada cuci darah, sementara di Indonesia saja saat ini ada sekitar 70 ribu penderita gagal ginjal kronik dan $10 \%$ nya memerlukan cuci darah (Imelda, Susalit, Marbun, \& Rumende, 2017; Nugroho, 2017).

Hasil penelitian lain menunjukkan bahwa rentang usia responden pada penelitiannya yaitu dari usia 18-64 tahun, meningkatnya usia seseorang memberikan dampak pada penurunan fungsi - fungsi tubuh sehingga semakin rentan terhadap penyakit. Umur pasien yang semakin meningkat juga berkaitan dengan prognosis suatu penyakit dan harapan hidup. Pada penderita yang berusia di atas 55 tahun lebih mudah untuk terjadinya suatu komplikasi yang dapat 
Faktor yang berhubungan dengan tingkat depresi pada pasien gagal ginjal kronis yang menjalani tindakan hemodialisa

memperberat fungsi ginjal untuk bekerja dibandingkan dengan penderita yang usianya di bawah 40 tahun. Dalam penelitian ini didapatkan responden dengan rentang usia 18-44 tahun berjumlah 24 responden $(51,08 \%)$ dan responden dengan rentang usia 45-65 tahun berjumlah 23 responden (48,93\%) (Putri, Sembiring, \& Bebasari, 2014; Yulianto, \& Basuki, 2017; Jamila, \& Herlina, 2019).

Menurut data dari medical record RSUD dr. Slamet Garut, jumlah pasien gagal ginjal kronis yang rutin menjalani hemodialisa selama tahun 2015 sebanyak 64 orang, sedangkan di Rumah Sakit TNI-AD Guntur Garut selama tahun 2011 sebanyak 19 pasien (Urdal RS TNI-AD Guntur Garut, 2016). Pada beberapa kasus gagal ginjal kronis, meskipun telah dilakukan hemodialisa secara berkala tetapi tetap saja memiliki risiko kematian yang cukup tinggi, menurut data dari ruang Hemodialisa RSUD dr. Slamet Garut, jumlah pasien yang meninggal sejak bulan Januari sampai bulan November 2017 sebanyak 7 orang dari 40 orang pasien hemodialisa. Kondisi ini tentunya merupakan salah satu stressor terjadinya kegelisahan, ketegangan, kecemasan dan depresi pada pasien gagal ginjal kronis yang sedang menjalani hemodialisa.

Dari hasil studi pendahuluan peneliti mewawancarai sepuluh orang pasien gagal ginjal kronik yang sedang menjalani hemodialisa dan diperoleh hasil bahwa ada 6 orang terlihat adanya tanda-tanda pasien gelisah, cemas, putus asa dan merasa tertekan selama menjalani terapi hemodialisa serta 4 orang mengatakan ingin berhenti melakakukan terapi hemodialisa, perasaan sedih, gangguan pola tidur, tidak bisa berkonsentrasi dan nafsu makan berkurang, usia mereka bervariasi, jenis kelamin yang menjalani terapi hemodialisa kebanyakan pria, rata-rata mereka sensitif, kebanyakan pendidikannya menengah kebawah, selain itu mereka tampak kebanyakan menutup diri.

\section{METODE PENELITIAN}

Penelitian deskriptif korelatif untuk melihat hubungan antara dua variable dengan desain penelitian menggunakan pendekatan cross sectional. Populasinya semua klien gagal ginjal kronik yang sedang menjalani hemodialisa secara rutin di RSUD Garut sebanyak 64 orang. Teknik pengambilan sampel dengan cara random sampling didapatkan sebanyak 40 responden. Instrumen yang digunakan sudah baku diambil dari alat ukur Hamilton Rating Scale for Depression (Hawari, 2009).

Untuk mengetahui sejauhmana derajat menggunakan alat ukur (instrumen) yang dikenal dengan nama Hamilton Rating Scale for Depression (HRS-D). Alat ukur ini terdiri dari 21 kelompok gejala yang masing-masing kelompok dirinci lagi dengan gejala-gejala yang lebih spesifik. Masing-masing kelompok gejala diberi penilaian angka (score) antara 0-4, yang artinya adalah :Nilai : 0 = tidak ada gejala, $1=$ gejala ringan, 2 = gejala sedang, 3 = gejala berat dan 4 = gejala berat sekali. Adapun kriteria hasil apabila total nilai (score) : < 17 = tidak ada depresi; 18-24 = depresi ringan; $25-34=$ depresi sedang; dan 35-51= depresi berat.

Untuk mencari hubungan antar variabel karakteristik digunakan uji statistik Chi - Square. Interpretasi hasil apabila nilai $p$-value $\leq 0,05$ berarti didapatkan ada hubungan. Jadi dapat disimpulkan bahwa $\mathrm{H}_{1}$ diterima; Bila nilai $p$-value $>0,05$ berarti didapatkan tidak ada hubungan. Jadi dapat disimpulkan bahwa $\mathrm{H}_{0}$ diterima. 
HASIL

Tabel 1. Distribusi Karakteristik Responden $\mathrm{N}=40$

\begin{tabular}{lcc}
\hline Variabel & Frekuensi (f) & Persentase (\%) \\
\hline Umur & 20 & 50 \\
$\quad$ Pertengahan & 20 & 50 \\
Lanjut & & \\
Pendidikan & 5 & 13 \\
$\quad$ Tinggi & 22 & 55 \\
Menengah & 13 & 32 \\
$\quad$ Dasar & & \\
& & \\
Jenis Kelamin & 13 & 33 \\
$\quad$ Perempuan & 27 & 67 \\
$\quad$ Laki-laki & & \\
& & \\
Jangka Waktu & 18 & 45 \\
$\quad$ Baru & 22 & 55 \\
Lama & & \\
Pola Tidur & & 35 \\
$\quad$ Cukup & 14 & 65 \\
Kurang & 26 & 60 \\
Tingkat Depresi & & 30 \\
Berat & & 10 \\
Sedang & 24 & \\
Ringan & 12 & \\
\hline
\end{tabular}

Berdasarkan table 1 diketahui bahwa responden yang berumur pada kelompok pertengahan dan kelompok usia lanjut sama jumlahnya; berpendidikan menengah (55\%); berjenis kelamin laki-laki $(67,50 \%)$. menjalani terapi hemodialisa lebih dari satu tahun $(55,50 \%)$; memiliki pola tidur kurang $(65,0 \%)$; dan menderita depresi berat $(60 \%)$. 
Faktor yang berhubungan dengan tingkat depresi pada pasien gagal ginjal kronis yang menjalani tindakan hemodialisa

Tabel 2. Hubungan Variabel Bebas dan Variabel Terikat

\begin{tabular}{|c|c|c|c|c|c|c|c|c|c|c|}
\hline \multirow{3}{*}{ Variabel } & \multicolumn{6}{|c|}{$\begin{array}{c}\text { Tingkat Depresi } \\
\end{array}$} & & & \multirow{3}{*}{$X^{2}$} & \multirow{3}{*}{$p$-value } \\
\hline & \multicolumn{2}{|c|}{ Ringan } & \multicolumn{2}{|c|}{ Sedang } & \multicolumn{2}{|c|}{ Berat } & \multicolumn{2}{|c|}{ Jumlah } & & \\
\hline & (n) & $\%$ & (n) & $\%$ & (n) & $\%$ & $\mathbf{N}$ & $\%$ & & \\
\hline \multicolumn{11}{|l|}{ Umur } \\
\hline Pertengahan & 5 & 13 & 9 & 23 & 6 & 15 & 20 & 50 & 15,45 & 0,000 \\
\hline Lanjut & - & - & 2 & 5 & 18 & 45 & 20 & 50 & & \\
\hline \multicolumn{11}{|l|}{ Jenis Kelamin } \\
\hline Laki-laki & 1 & 2 & 5 & 12 & 21 & 53 & 27 & 67 & 11,95 & 0,003 \\
\hline Perempuan & 4 & 10 & 6 & 15 & 3 & 8 & 13 & 33 & & \\
\hline \multicolumn{11}{|l|}{ Pendidikan } \\
\hline Tinggi & - & - & 1 & 2 & 4 & 11 & 5 & 13 & 35,87 & 0,000 \\
\hline Menengah & 1 & 2 & 4 & 11 & 17 & 42 & 22 & 55 & & \\
\hline Dasar & 4 & 11 & 6 & 15 & 3 & 6 & 13 & 32 & & \\
\hline \multicolumn{11}{|c|}{ Jangka Waktu Terapi } \\
\hline \multicolumn{11}{|c|}{ Hemodialisis } \\
\hline Baru & 4 & 11 & 11 & 28 & 3 & 6 & 18 & 45 & 26,16 & 0,000 \\
\hline Lama & 1 & 2 & - & - & 21 & 53 & 22 & 55 & & \\
\hline \multicolumn{11}{|l|}{ Pola Tidur } \\
\hline Cukup & 3 & 6 & 9 & 24 & 2 & 5 & 14 & 35 & 35,87 & 0,000 \\
\hline Kurang & 6 & 15 & 6 & 15 & 14 & 35 & 26 & 65 & & \\
\hline
\end{tabular}

Berdasarkan table 2 tersebut diatas tampak usia petengahan responden sebagian kecil responden (23\%) mengalami depresi sedang, sedangkan pada usia lanjut hampir separuhnya responden $(45 \%)$ mengalami depresi berat. Dari perhitungan diatas diperoleh chi-square $\left(X^{2}\right)=$ $15,45, p$-value $=0.000$. Dengan $X^{2}=19.52$ dan nilai $p$-value-nya adalah $0.000<0.05$, pada taraf signifikansi 0,05 maka dapat disimpulkan bahwa terdapat hubungan yang signifikan antara usia responden dengan tingkat depresi

Untuk jenis kelamin laki-laki sebagian besar responden $(53 \%)$ mengalami depresi berat, sedangkan pada perempuan sebagian kecil responden $(15 \%)$ mengalami depresi sedang. Dari perhitungan diatas diperoleh chi-square $\left(X^{2}\right)=$ 11,95, $p$-value $=0.003$. Dengan $X^{2}=11,95$ dan nilai $p$-value-nya adalah $0.000<0.05$, pada taraf signifikansi 0,05 maka dapat disimpulkan bahwa terdapat hubungan yang signifikan antara jenis kelamin responden dengan tingkat depresi

Untuk responden yang memiliki pendidikan tinggi dan menengah hampir seluruhnya responden $(11 \%)$ dan (42\%) mengalami depresi berat. Dari perhitungan diatas diperoleh chi-square
$\left(X^{2}\right)=35,87, p$-value $=0.000$. Dengan $X^{2}=11,95$ dan nilai $p$-value-nya adalah $0.000<0.05$, pada taraf signifikansi 0,05 maka dapat disimpulkan bahwa terdapat hubungan yang signifikan antara pendidikan responden dengan tingkat depresi

Sedangkan pada responden yang telah lama melakukan terapi hemodialisa hampir seluruh responden $(53 \%)$ menderita depresi berat dan yang baru melakukan terapi hemodialisa lebih dari setengah responden $(28 \%)$ berada pada depresi sedang. Dari perhitungan diatas diperoleh chisquare $\left(x^{2}\right)=26,16, p$-value $=0.000$. Dengan $x^{2}=$ 26,16 dan nilai $p$-value-nya adalah $0.000<0.05$, pada taraf signifikansi 0,05 maka dapat disimpulkan bahwa terdapat hubungan yang signifikan antara jangka waktu melaksanakan terapi hemodialisa dengan tingkat depresi

Untuk responden yang memiliki pola tidur kurang sebagian besar responden (35\%) mengalami tingkat depresi berat dan yang memiliki pola tidur cukup sebagian besar responden (24\%) mengalami tingkat depresi sedang. Dari perhitungan diatas diperoleh chi-square $\left(X^{2}\right)=$ $35,87, p$-value $=0.000$. Dengan $X^{2}=11,95$ dan nilai $p$-value-nya adalah $0.000<0.05$, pada taraf 
Faktor yang berhubungan dengan tingkat depresi pada pasien gagal ginjal kronis yang menjalani tindakan hemodialisa

signifikansi 0,05 maka dapat disimpulkan bahwa terdapat hubungan yang signifikan antara pola tidur responden dengan tingkat depresi

\section{PEMBAHASAN}

Hasil penelitian yang menyatakan adanya hubungan yang signifikan antara usia dengan tingkat depresi, sejalan dengan teori konsep depresi bahwa semakin bertambah usia maka semakin tinggi seseorang mengalami tingkat depresi terutama diatas 55 tahun (Prabhaswari, \& Ariastuti, 2015; Lumongga, 2016; Nababan, Ani, \& Yuliyatni, 2017). Hal ini juga sesuai terhadap hasil penelitian yang penulis hasilkan bahwa dari hasil pengolahan data dapat dubuktikan pada kelompok usia lanjut (> 55 tahun) tingkat depresi lebih tinggi dibandingkan dengan usia pertengahan (35-55 tahun).

Hubungan yang signifikan juga didapatkan antara tingkat pendidikan dengan tingkat depresi, sejalan dengan teori yang menyatakan bahwa dengan tingkat pendidikan menyebabkan pengetahuan dan wawasan seseorang menjadi luas, memahami dan mengetahui bagaimana cara pemeliharaan dan perawatan kesehatan yang baik, dengan pendidikan yang tinggi mampu mengendalikan diri (Notoatmodjo, 2015).

Pada pendidikan yang lebih tinggi sesorang akan lebih memahami tentang penyakitnya, sejalan dengan pemahaman yang luas tentang penyakitnya maka yang bersangkutan cenderung lebih mudah terserang depresi, hasil ini menunjukan bahwa pendidikan berpengaruh positif terhadap kejadian depresi.

Hubungan jenis kelamin dengan tingkat depresi menunjukan adanya hubungan signifikan, kondisi ini sesuai pendapat yang mengatakan bahwa pria memang rentan dengan penyakit gagal ginjal kronik daripada perempuan. Keseharian aktifitas pria umumnya lebih banyak menggunakankan tenaga fisik, bekerja keras, lupa minum dan pola makan yang tidak baik (Santoso, 2014; Fauziyati, 2017).

Sedangkan dari tingkat depresi pada penilitian tampak pria lebih tinggi dibandingkan dengan perempuan, hal ini dimungkinkan karena jumlah sampel penderita gagal ginjal didominasi pria. Sedangkan dari depresi sejalan dengan pendapat peneliti lain yang menyatakan bahwa wanita dua kali lebih sering terdiagnosis menderita depresi daripada pria. Bukan berarti wanita lebih mudah terserang depresi, bisa saja karena wanita lebih sering mengakui adanya depresi dari pada pria dan dokter lebih dapat mengenali depresi pada wanita (Purnamasidhi, \& Kuswardhani, 2016; Subedi, Shrestha, \& Thapa, 2018). Melihat kondisi ini memang terdapat hubungan jenis kelamin terhadap kejadian depresi pada seseorang. Menurut peneliti dengan hasil penelitian ini menunjukan bahwa jenis kelamin mempengarhi tingkat depresi seseorang dan hasil penelitian inipun menunjukan bahwa wanita cenderung mudah mengalami depresi.

Hasil penelitian ini juga menunjukan adanya hubungan antara jangka waktu melakukan hemodialisa dengan tingkat depresi. Hal ini sejalan dengan pendapat peneliti lain yang menyatakan bahwa seseorang yang ditempatkan untuk waktu yang lama dalam situasi dimana mereka tidak punya kekuatan dan tidak dapat melarikan diri lebih mudah terserang depresi (Sulistini, Yetti, \& Hariyati, 2012; Suparti, \& Nurjanah, 2018).

Hasil ini menurut pendapat peneliti menunjukan bahwa jangka waktu sesorang melakukan hemodialisa akan mempengaruhi tingkat depresi seseorang, dari hasil penelitianpun menunjukan bahwa semakin lama seseorang menjalani hemodialisa maka semakin tinggi tingkat depresinya. Hubungan antara pola tidur yang melakukan hemodialisa dengan tingkat depresi menunjukan hubungan yang signifikan. Pendapat peneliti bahwa sesuai hasil penelitian dengan pola tidur yang kurang seseorang akan lebih mudah mengalami tingkat depresi. Semakin kurang seseorang memperoleh kesempatan tidur maka akan menyebabkan kegelisahan, ketegangan, gangguan pikiran, kurang istirahat dan akibatnya menjadi cemas dan berlanjut ke depresi.

\section{SIMPULAN}

Berdasarkan hasil penelitian yang telah
dilakukan mengenai faktor-faktor yang
berhubungan dengan tingkat depresi, dapat
disimpulkan bahwa : Adanya hubungan antara
faktor usia, faktor pendidikan, faktor jenis kelamin,
faktor jangka waktu melaksanakan terapi
hemodialisa dan factor pola tidur dengan tingkat
depresi pada pasien gagal ginjal kronik yang
menjalani tindakan hemodialisa di Ruang
Hemodialisa RSUD dr. Slamet Garut.

\section{SARAN}

Berdasarkan kesimpulan tersebut maka peneliti menyarankan agar pihak institusi selalu 
Faktor yang berhubungan dengan tingkat depresi pada pasien gagal ginjal kronis yang menjalani tindakan hemodialisa

meningkatkan pengetahuan pasien dan pemahaman pentingnya melakukan terapi hemodialisa pada pasien gagal ginjal kronik untuk mengurangi dan menghilangkan depresi yang dialami dengan mengikutsertakan pihak keluarga sebagai pola dukungan.

\section{DAFTAR PUSTAKA}

Anggraini, Y. D. (2016). Kualitas hidup pasien gagal ginjal kronis yang menjalani hemodialisis di RSUD Blambangan Banyuwangi.

Faizzah, E. N. (2017). Perbedaan tingkat kecemasan dan depresi pada pasien yang menjalani hemodialisis di RSUD Prof. Dr. Margono Soekarjo Purwokerto (Doctoral dissertation, Universitas Muhammadiyah Purwokerto).http://repository.ump.ac.id/4001/3/ ELISA\%20NUR\%20FAIZZAH\%20BAB\%20II.pd $f$

Fauziyati, A. (2017). Global challenge of early detection and management of chronic kidney disease. Jurnal Kedokteran dan Kesehatan Indonesia, 8(1), 1 2.https://media.neliti.com/media/publications/13 7218-EN-global-challenge-of-early-detectionand.pdf

Hawari,D. (2014).Manajemenstres,cemas dan depresi.Edisi kedua cetakan keempat.Jakarta:FKUI.

https://repository.unej.ac.id/bitstream/handle/12 3456789/76659/Yunita\%20Dwi\%20Anggraini\% 20-\%20112110101135\%20-1.pdf?sequence=1

Hutajulu, J. (2018). Hubungan pengetahuan pasien ckd yang menjalankan hemodialisis tentang diet dengan kepatuhan menjalankan diet ckd di instalasi dialisis RSUD dr. Pirngadi Medan tahun 2017. Jurnal online keperawatan indonesia, 1(1), 75-91.http://e-journal.sarimutiara.ac.id/index.php/Keperawatan/article/vie $w / 373 / 352$
Imelda, F., Susalit, E., Marbun, M. B. M., \& Rumende, C. M. (2017). Gambaran Klinis dan Kualitas Hidup Pasien Penyakit Ginjal Tahap Akhir yang Menjalani Hemodialisis Dua Kali Dibandingkan Tiga Kali Seminggu. Jurnal Penyakit Dalam Indonesia, 4(3), 128136.http://jurnalpenyakitdalam.ui.ac.id/index.ph p/jpdi/article/view/139/125

Jamila, I. N., \& Herlina, S. (2019). Study comparatif kualitas hidup antara pasien hemodialisis dengan pasien continuous ambulatory peritoneal dialysis (CAPD). Journal of Islamic Nursing, 4(2), $\quad$ 54-59.http://journal.uinalauddin.ac.id/index.php/join/article/view/10025/ 7251

Lase, W. N. (2011). Analisis Faktor-Faktor yang Mempengaruhi Kualitas Hidup Pasien Gagal Ginjal Kronis yang Menjalani Hemodialisa di RSUP Haji Adam Malik Medan.http://repository.usu.ac.id/bitstream/han dle/123456789/27561/Chapter\%20Il.p?sequen ce $=4$

Lumongga, D. N. (2016). Depresi: tinjauan psikologis. Kencana.

Nababan, C. C. M., Ani, L. S., \& Yuliyatni, P. C. D. (2017). Kejadian dan karakteristik depresi pada usila (usia lanjut) di wilayah kerja puskesmas Manggis II tahun 2017. E-Jurnal Medika Udayana, 8(7).https://ojs.unud.ac.id/index.php/ eum/article/view/51801/30724

Notoatmodjo, S. (2015). Pendidikan dan Perilaku Kesehatan. Jakarta : PT Asdi Mahasatya.

Novitasari, I., \& Hidayati, W. (2015). Gambaran Tingkat Kecemasan, Stres, Depresi dan Mekanisme Koping Pasien Penyakit Ginjal Kronik yang Menjalani Hemodialisis di RSUD Dr. Moewardi (Doctoral dissertation, Faculty of Medicine).http://eprints.undip.ac.id/51787/1/Pro posal_Gambaran_Tingkat_Kecemasan.Pdf 
Faktor yang berhubungan dengan tingkat depresi pada pasien gagal ginjal kronis yang menjalani tindakan hemodialisa

Nugroho, P. (2017). Apakah Hemodialisis Tiga Kali Seminggu Lebih Baik?. Jurnal Penyakit Dalam Indonesia, 4(3), 103104.http://jurnalpenyakitdalam.ui.ac.id/index.ph p/jpdi/article/viewFile/142/127

Nurmalika, A. (2010). Hubungan antara self control dengan kecemasan pasien gagal ginjal kronik di Yayasan Ginjal Diatras Indonesia. http://repository.uinjkt.ac.id/dspace/bitstream/12 3456789/1233/1/ADE\%20NURMALIKA\%20FPS.pdf

Prabhaswari, L., \& Ariastuti, N. L. P. (2015). Gambaran kejadian depresi pada lanjut usia di wilayah kerja Puskesmas Petang I Kabupaten Badung Bali 2015. ISM. Bali, 7(1), 16.http://sage.ejournals.ca/isainsmedis.id/index. php/ism/article/viewFile/100/101

Purnamasidhi, C. A. W., \& Kuswardhani, R. T. (2016). High interleukin-6 level increases depression risk on geriatric population in Denpasar, Bali-Indonesia. Bali Medical Journal, 5(3), $37-$ 41.https://pdfs.semanticscholar.org/fcee/280e2 614bba5b494ed0093c92768ebad6975.pdf

Putri, R., Sembiring, L. P., \& Bebasari, E. (2014). Gambaran Kualitas Hidup Pasien Gagal Ginjal Kronik Yang Menjalani Terapi Continuous Ambulatory Peritoneal Dialysis Di RSUD Arifin Achmad Provinsi Riau Dengan Menggunakan Kuesioner KDQOLSFTM (Doctoral dissertation, Riau University).https://media.neliti.com/media/public ations/185103-ID-gambaran-kualitas-hiduppasien-gagal-gin.pdf

Rahman, M. T., Kaunang, T. M., \& Elim, C. (2016). Hubungan antara lama menjalani hemodialisis dengan kualitas hidup pasien yang menjalani hemodialisis di Unit Hemodialisis RSUP. Prof. Dr. RD Kandou Manado. e-
CliniC, 4(1).https://ejournal.unsrat.ac.id/index.p hp/eclinic/article/viewFile/10829/10418

Romadhoni, M. (2012). Hubungan antara Penyesuaian Diri dengan Kebermaknaan Hidup pada Penderita Penyakit Ginjal Kronik di RSUD Banyumas (Doctoral dissertation, Universitas Muhammadiyah

Purwokerto).http://repository.ump.ac.id/5201/3/ MARDINA\%20ROMADHONI\%20BAB\%20II.pdf

Santoso, D. (2014). Membangun Paradigma Baru: Menuju Kesehatan Ginjal Berbasis Pencegahan.http://repository.unair.ac.id/40076/ 1/gdlhub-gdl-grey-2016-santosodjo-40463pg.07-14-m.pdf

Subedi, S., Shrestha, P., \& Thapa, D. K. (2018). Study Of Depression in Elderly: Prevalence and Factors Associated. Journal of Psychiatrists' Association of Nepal, 7(2), 1623.https://www.nepjol.info/index.php/JPAN/artic le/view/24609

Sulistini, R., Yetti, K., \& Hariyati, R. T. S. (2012). Faktor Faktor yang Mempengaruhi Fatigue Pada Pasien yang Menjalani Hemodialisis. Jurnal Keperawatan Indonesia, 15(2), 7582.http://www.jki.ui.ac.id/index.php/jki/article/vie wFile/30/30

Suparti, S., \& Nurjanah, S. (2018). Hubungan Depresi dengan Fatigue pada Pasien Hemodialisis. Ejournal Unisa Yogya, 2(01).https://pdfs.semanticscholar.org/7 7d2/857f1dd463a82ff423a09e232801291957e5 .pdf

Tokala, B. F., Kandou, L. F., \& Dundu, A. E. (2015). Hubungan antara lamanya menjalani hemodialisis dengan tingkat kecemasan pada pasien dengan penyakit ginjal kronik di RSUP Prof. Dr. RD Kandou Manado. e- 
Faktor yang berhubungan dengan tingkat depresi pada pasien gagal ginjal kronis yang menjalani tindakan hemodialisa

CliniC, 3(1).https://ejournal.unsrat.ac.id/index.p hp/eclinic/article/viewFile/7395/6938

Wijayanti, D., Dinarwiyata, D., \& Tumini, T. (2018). Self Care Management Pasien Hemodialisa Ditinjau Dari Dukungan Keluarga Di Rsud Dr. Soetomo Surabaya. Jurnal IImu Kesehatan, 6(2), 109117.https://www.ejurnaladhkdr.com/index.php/ji k/article/view/162/139

Wong, O. A., \& Sarjana, D. S. S. M. G. (2017). Analisis perubahan hemoglobin pada pasien gangguan ginjal kronik (GGK) yang menjalani Hemodialisa selama 3 Bulan di Rumah Sakit Perguruan Tinggi Negeri (RSPTN) Universitas Hasannudin (UNHAS) Makassar [skripsi].http://digilib.unhas.ac.id/uploaded_files/ temporary/DigitalCollection/NTQ0MDU3ZDc5M zEzYWNiYmU4MDBhYjY5ZDk1YTgxOTVmNz EOMjUxNg==.pdf
Yulianto, D., \& Basuki, H. (2017). Analisis ketahanan hidup pasien penyakit ginjal kronis dengan hemodialisis di RSUD Dr. Soetomo Surabaya. Jurnal Manajemen Kesehatan Yayasan RS. Dr. Soetomo, 3(1), 96108.http://jurnal.stikesyrsds.ac.id/index.php/JMK/article/view/92/90 